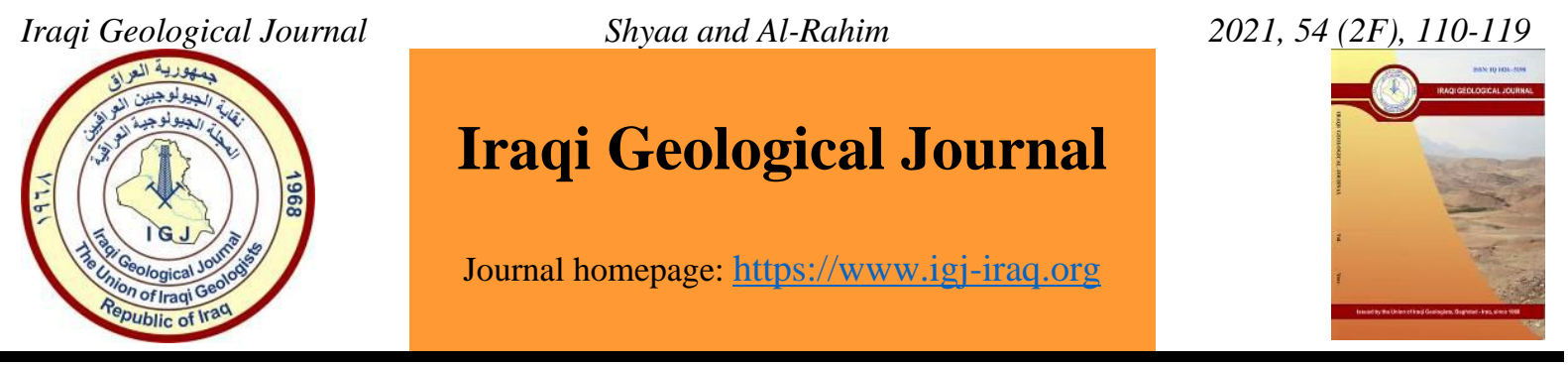

\title{
Updating Subsurface Image of Khashim Al-Ahmer Gas Field Using the Interpretation for Anisotropic Velocity Model North-Eastern Iraq
}

\author{
Yasir F. Shyaa ${ }^{1, *}$ and Ali M. Al-Rahim ${ }^{1}$ \\ 1 Department of Geology, College of Science, University of Baghdad, Baghdad, Iraq \\ * Correspondence: yasirfalih@gmail.com
}

Received: 18 September 2021; Accepted: 14 October 2021; Published: 31 December 2021

\begin{abstract}
This research deals with structural interpretation of Khashim Al-Ahmer Gas Field North-Eastern Iraq in Diyala Province, using the interpretation of inhomogeneous velocity data. The specific target in this field is the gaseous Jeribe reservoir representing the L. Miocene-Tertiary period. A very thick layer of evaporates Al-Fatha Formation is overlap the Jeribe Formation in the gas field and play as a sealed bed and transition zone for faults movement as a thrust fault. The thrust fault with gas content negatively affected the seismic energy, causing a high attenuation below the level of Al-Fatha Formation in the dome of the Khashm Al-Ahmer structure. Using the interval velocities derived from the sonic logs of five surrounding wells that represent the inhomogeneous behavior of the seismic wave velocity within the rock layers, a model of the velocity behavior in the field was built and the extent of the Jeribe gas reservoir was reconstructed according to the new velocities interpretation data.
\end{abstract}

Keywords: Anisotropic velocity; Interpretation velocity; Sonic logs; Khashim Al-Ahmer Gas Field

\section{Introduction}

Lateral velocity variations related with complex overburden structures complicate earth imaging in depth in processing seismic data. examples for complex overburden are diapiric structures created by salt tectonics, imbricate structures created via overthrust tectonics and irregular water-bottom topography. All these three are describe as structure-following lateral velocity variations. There also occur structure-independent lateral velocity variations, overwhelmingly related with facies changes; for instance, changes in lithology from shale to sandstone to carbonate induce lateral changes in acoustic impedance, (Yilmaz, 2001). In seismic work, the term velocity commonly refers to the propagation rate of the seismic wave in the medium in which it's propagating. Heterogeneity factor basically gives the closest representation of velocity heterogeneity in the ground. Geoscientist is obliged to work with a macro model, a simplified velocity model of the subsurface that invariably involves an assumption of various degrees of (or, sometimes, total) homogeneity in simulating the true subsurface which is invariably heterogeneous, (Al-Chalabi, 2014). From a practical perspective, the heterogeneity factor computed from the sonic (velocity) log which is practically always close to the asymptote value should be fully adequate for most applications, (Backus, 1962). Khashim Al-Ahmer Gas Field which is located at the north-eastern part of Iraq is an example of such complex overburden structure. This field is a part

DOI: 10.46717/igj.54.2F.10ms-2021-12-27 
of three main structures named (Mansuriya, Khashim Al-Ahmer and Injana). This field is characterized by thrust fault within very thick in thickness formation, Al-Fatha Formation (M. Miocene). Previous study for the velocity model of this structure is depended on the data form one single well, and this is not suitable for such complex structure. The aim of the current study is to update the subsurface image for the Khashim Al-Ahmer gas field using data from many surrounding wells and putting into consideration the heterogeneity of the velocity data available in these wells. The study will be focus on developing the procedure of reprocessing and modelling the seismic data according to these new conditions.

\section{Location of the Study Area}

Khashim Al-Ahmer Gas Field is located at the north-eastern part of Iraq within Diyala Governorate, and approximately $70 \mathrm{~km}$ northeast centre of Baquba city as shown in Fig. 1 Five wells were used in this research to create the anisotropy velocity model, named respectively: Qumer1 (Qm1), Injana5 (In5), Mansuriya1 (Ms1), Khashim Al-Ahmer2 (KA2) and Galabat3 (Gt3) (Fig.1). The study area has two wells (KA1, KA2). Only KA2 has logging data because KA1 so old was drilled in period (1927-1928) and reached the transitional beds of the Fatha Formation and was abandoned due to gas blow up (for this reason, KA1 was not used), and perhaps the only information that can be used is to confirm the presence of gas in the field, (Khorshid, \& Owiad, 2015). The boundary of the study area according to the coordinate system Universal Transform Mercator projection UTM-WGS84, shown in Table 1.

Table 1. Coordinates boundaries (WGS84 UTM Zone38) WGS: World Geodetic System as datum. UTM: Universal Transverse Mercator as Projection

\begin{tabular}{ccc}
\hline Points & \multicolumn{2}{c}{ UTM System } \\
\hline & Easting & Northing \\
A & 462674 & 3803427 \\
B & 482247 & 3819551 \\
C & 501632 & 3796064 \\
D & 481687 & 3779940 \\
\hline
\end{tabular}

Tectonically, Khashim Al-Ahmer gas field is located in the unstable shelf, within Foothill the Hemrin-Makhul Subzone in North-Eastern of the Arabian Peninsula (Fig.2). The nowadays arrangement of the North-Eastern margin of the Arabian Plate is a result of continental collision (Fig.2). The NeoTethys Sea was closed in the end of Eocene Epoch. The Basin of Mesopotamian become shallower and narrower where the western part of the Arabian Peninsula has been thermally uplifted it was a very shallow lagoon in the beginning of the M. Miocene Epoch which the Jeribe Fn. was deposited. Further strong compression occurred in latest L. Miocene Epoch, which spread into the Mid Miocene foreland basin resulting in the growth of the large Zagros anticlines. A rapidly submergence foredeep basin formed in North and North-Eastern Iraq flanked by a thrust belt. An intermontane basin developed within the suture zone in which red beds were deposited, (Jassim and Goff, 2006). 


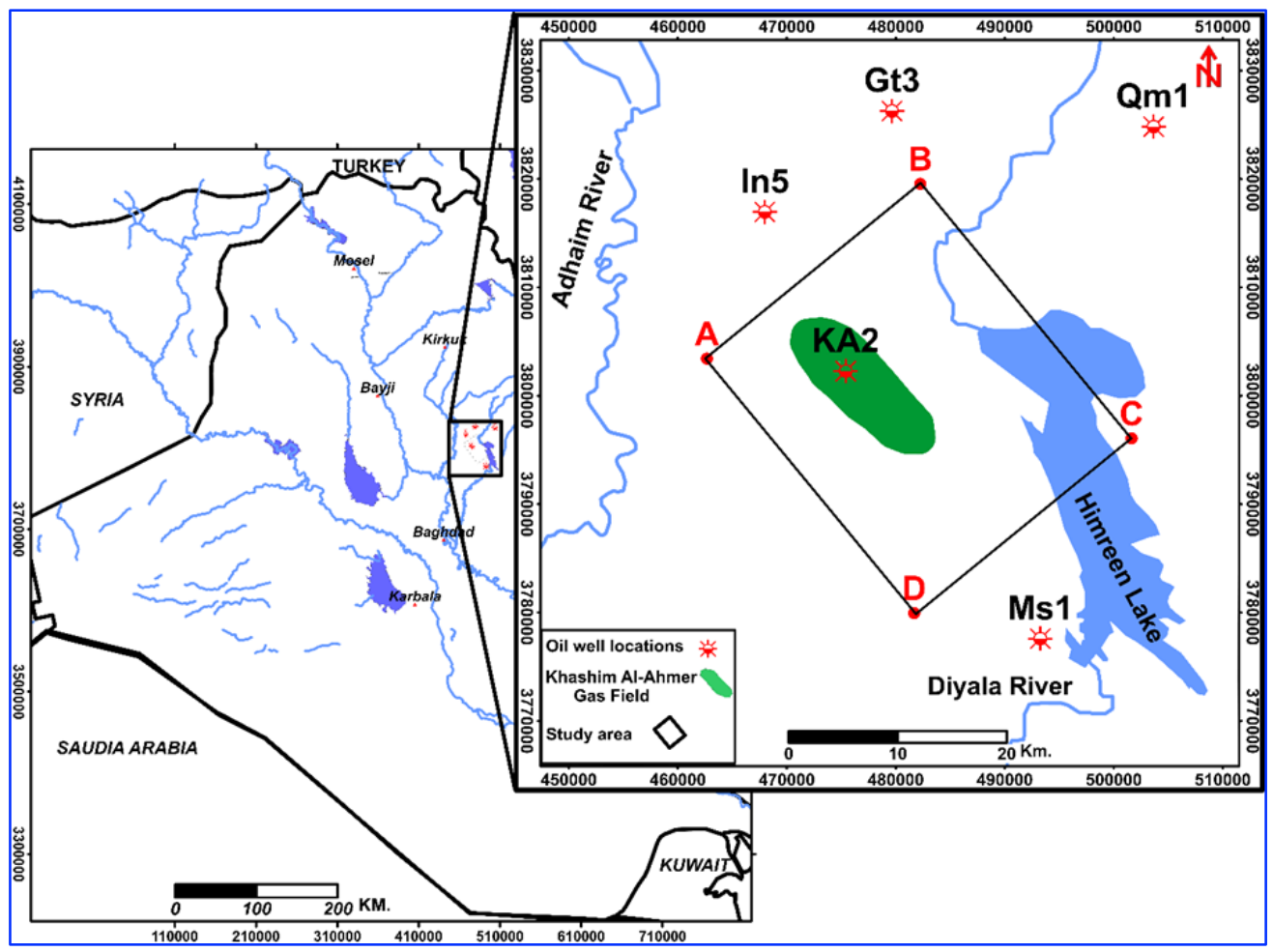

Fig.1. Illustrates location map of the study area and the five wells (KA2, Ms1, In5, Gt3, Qm1) sites which were used for building the velocity model

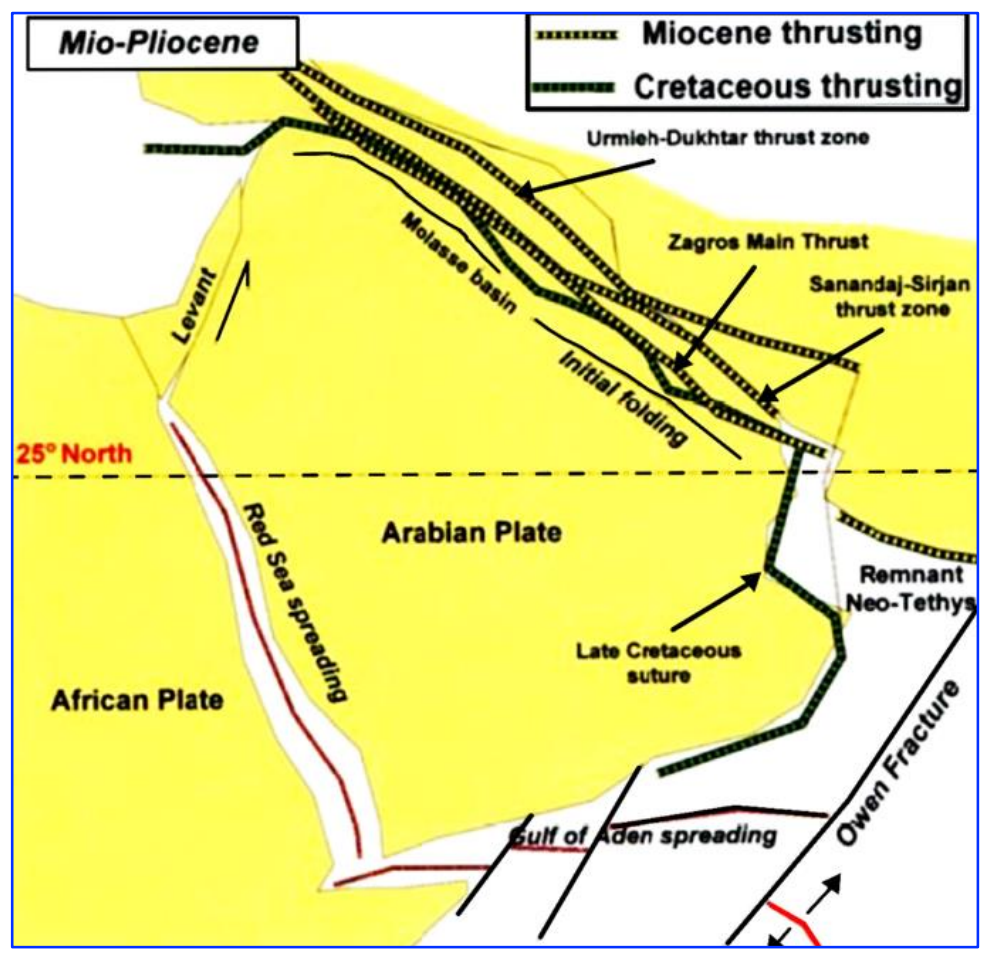

Fig.2. Illustrates the tectonic setting development of the Arabian Plate and North-Eastern of The Arabian Peninsula through Tertiary Period, (Jassim and Goff, 2006) 


\section{Methodology and Results}

\subsection{Generation of Synthetic Seismogram}

Based on convolving density logs data with interval velocity data will results acoustic impedance. The difference values as positive and negative through the geological beds with depth generate reflectivity. Design the wavelet is considered of deterministic to the signal behaviour of seismic and acoustic impedance well $\log$, and a correlation between the two signals at well point of the seismic section then determines the best predictive ratio of the signal behaviour that matches along the well depth of the seismic time section. The total output will generate synthetic seismogram (Fig. 3), which is used as geological formation indicator on time domain at a seismic section. Best fitting of the synthetic seismogram with the seismic section refers the best time depth relation (TDR), definitions top of the geological top formations on the seismic time section represented as the signal behaviour (positive, negative, S- crossing and Z- crossing) as shown in (Fig. 4) and depending on the physical formation properties whose outcome is the acoustic impedance, (AL-Banna \&Al-Karadaghi, 2018)

From the well located in the seismic section (PIK18) and from the signal behaviour of formations reflectors; picking has done. Along the seismic section by auto-tracing tool to keep the behaviour properties with distance, considered the faults effective were tracking before picking the seismic horizons which it shows thrust faults system at the upper part of the seismic section. The picked horizons are characterized by optimal reflectivity than other and presented as: Al-Fatha Formation (M. Miocene,Tertiary), Jeribe (L. Miocene, Tertiary), Dhiban (L. Miocene, Tertiary), Jaddala (Paleocene/Eocene, Tertiary).

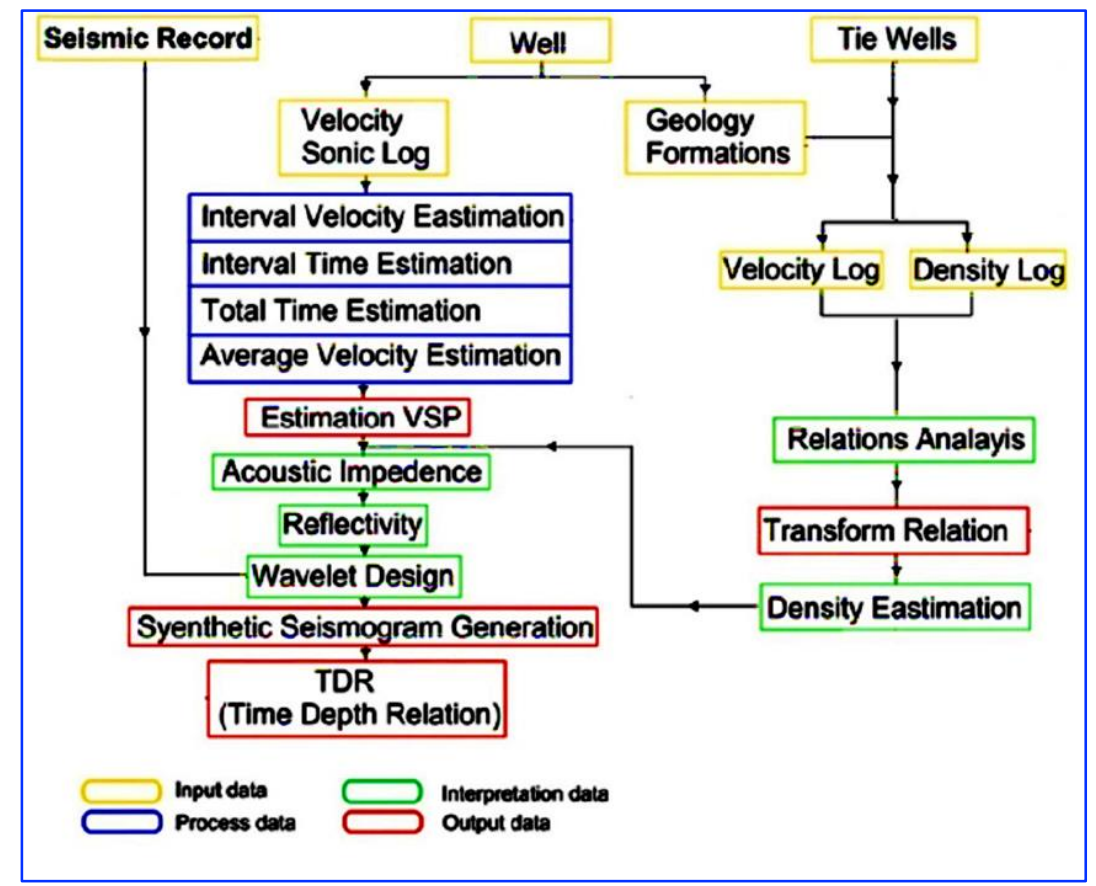

Fig.3. Illustrates the flowchart of seismic processing, well ties and output synthetic seismogram

After creating the synthetic seismogram and the process of identifying the reflectors, four horizons were picked and built for four formations (aforementioned), including the Jeribe Fn. which is the main target of being a gas reservoir. (Fig. 5) shows a clarify subsurface geological image in the Khashim AlAhmer structure area and represents a panoramic image of the seismic data with the Synthetic Seismogram of the (Well-KA2) and the picked formations. 


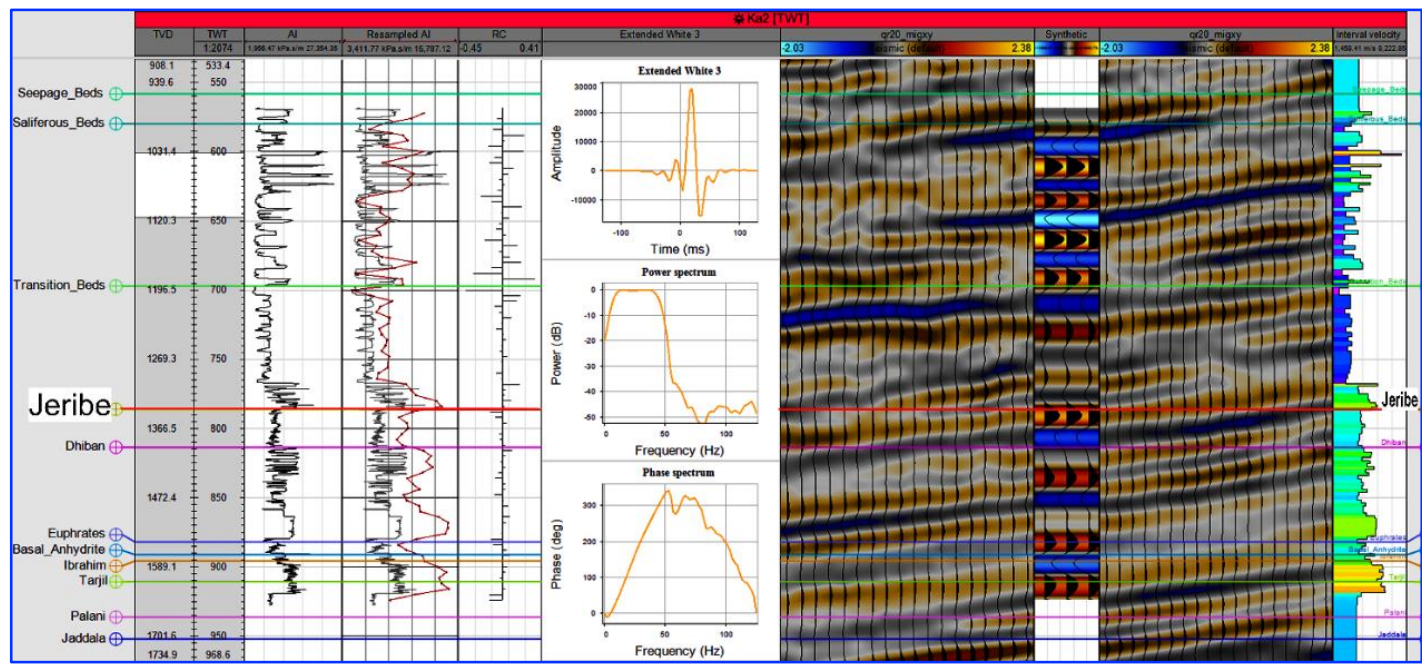

Fig.4. Illustrates synthetic seismogram of KA2 well generation by input (density \& velocity) $\operatorname{logs}$

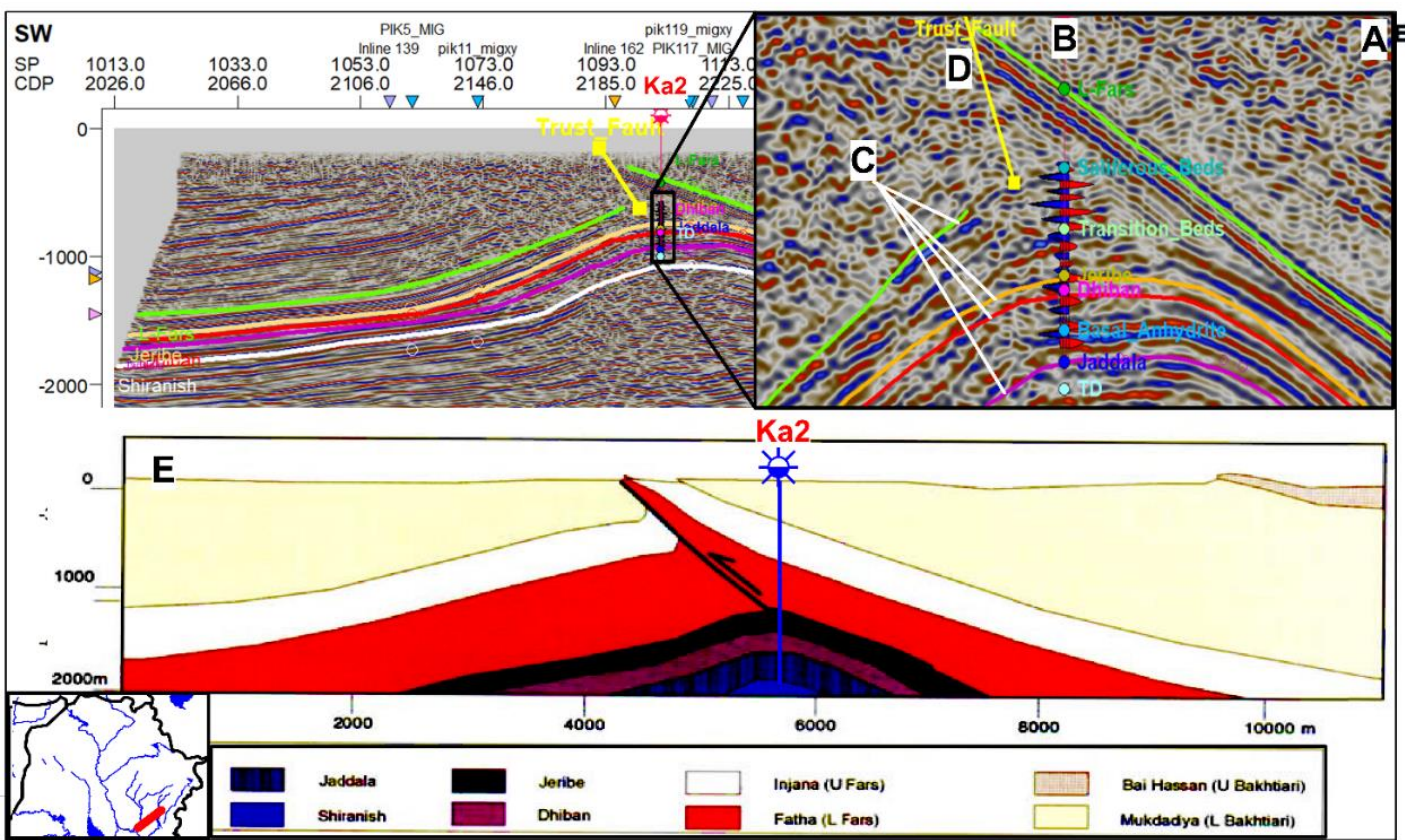

Fig.5. (A) Illustrates PIK18 seismic section, (B) include the synthetic seismogram, (C) four horizons picking, (D) thrust fault, and (E) the geological subsurface model

\subsection{Anisotropy Velocity Model}

In the geophysical seismic exploration, seismic waves are used to image the subsurface. These waves are travel through the earth and are reflected and refracted at sediment interfaces due to various velocity and density that influences on the pathway of the propagated waves. The returning signals are recorded at the surface by measuring terminated time from when the seismic signal is generated. The Earth is heterogeneous in nature, and thus, the propagation waves travel through various rocks in multiple direction at various velocities. This signify that "seismic waves travelling in one direction comparative to a vertical axis are spreading faster or slower than in another directions, an impact which varies aerially and with depth." (McBarnet, 2008). 
The anisotropy is seen in nearly all rocks affecting both compressional and shear waves in various ways. The directional and spatial effects of anisotropy can be hard to recognize when using only seismic data. The anisotropy engenders from organized heterogeneity at scales least than a seismic wavelength. There are various kinds of anisotropy and are categorized based on the degree and effect of anisotropy. The starting velocities can be calculated from P- sonic logs and horizon markers for each formation, (Tsvankin, 2001).

The sonic logs for the five wells were loaded into the petrel system and the interval velocity was derived from them, and then an anisotropy velocity model was built as shown in (Fig. 6). The process of creating the velocity model derivative from sonic logs is done by using petrel system, and the following is a brief explanation of this process, the scale up of well logs is an automatic process with some user settings available. When scaling up the well logs, Petrel will first find the 3D grid cells that the wells penetrate. For each grid cell, all log values that fall within the cell will be averaged according to the selected algorithm to produce one log value for that cell. The resulting $3 \mathrm{D}$ grid will only hold values for the 3D grid cells that the wells have penetrated.

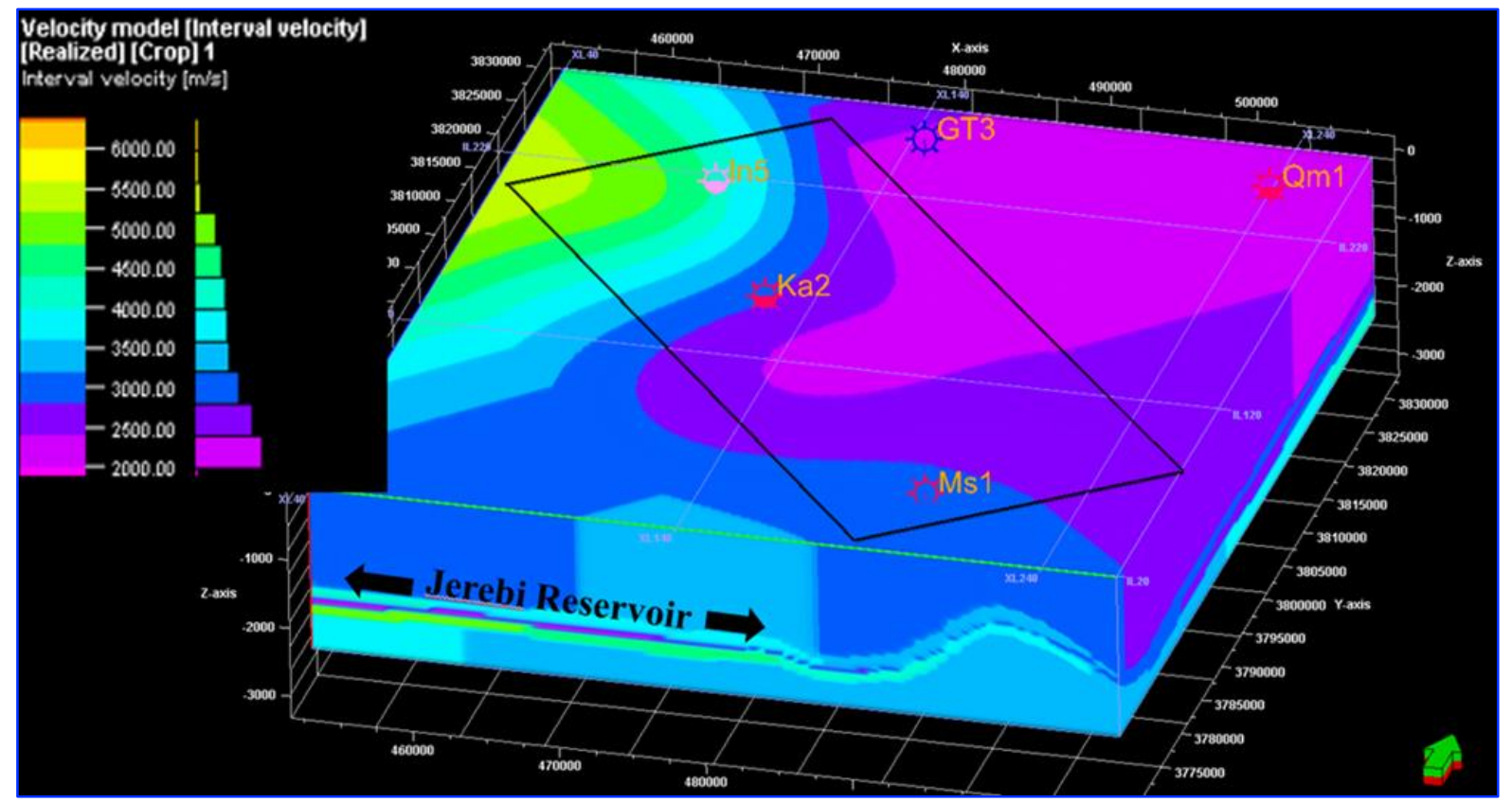

Fig.6. Illustrates anisotropy velocity model which was derived from five wells (KA2, Ms1, In5, Gt3, Qm1) located in the study area and its surroundings

\subsection{Anisotropy Velocity Interpretation}

As mentioned before, anisotropy velocity model (Fig. 6) is created using Petrel software from sonic logs data for five wells (KA2, Ms1, In5, Qm1, Gt3). The interpretation results for this model shows that the area is affected by a thrusting faults system at the level of the Al-Fatha Formation. (Fig. 7) Clearly shows this fault system on (PIK18) seismic line with interpretation. Also, anisotropic velocity section for the same line (Fig. 8) is illustrated the 2D anisotropy velocity section with synthetic seismogram for well KA2 and illustrated Jeribe reservoir with anisotropic velocity variation. It is noted that, the gas within Jeribe Fn. (The main reservoir in the field) is affected to decrease the seismic velocity wave in Khashim Al-Ahmer gas field, which is confirmed by this section represented by the (Violet) colour inside the Jeribe reservoir of value $(2300 \mathrm{~m} / \mathrm{sec})$. 


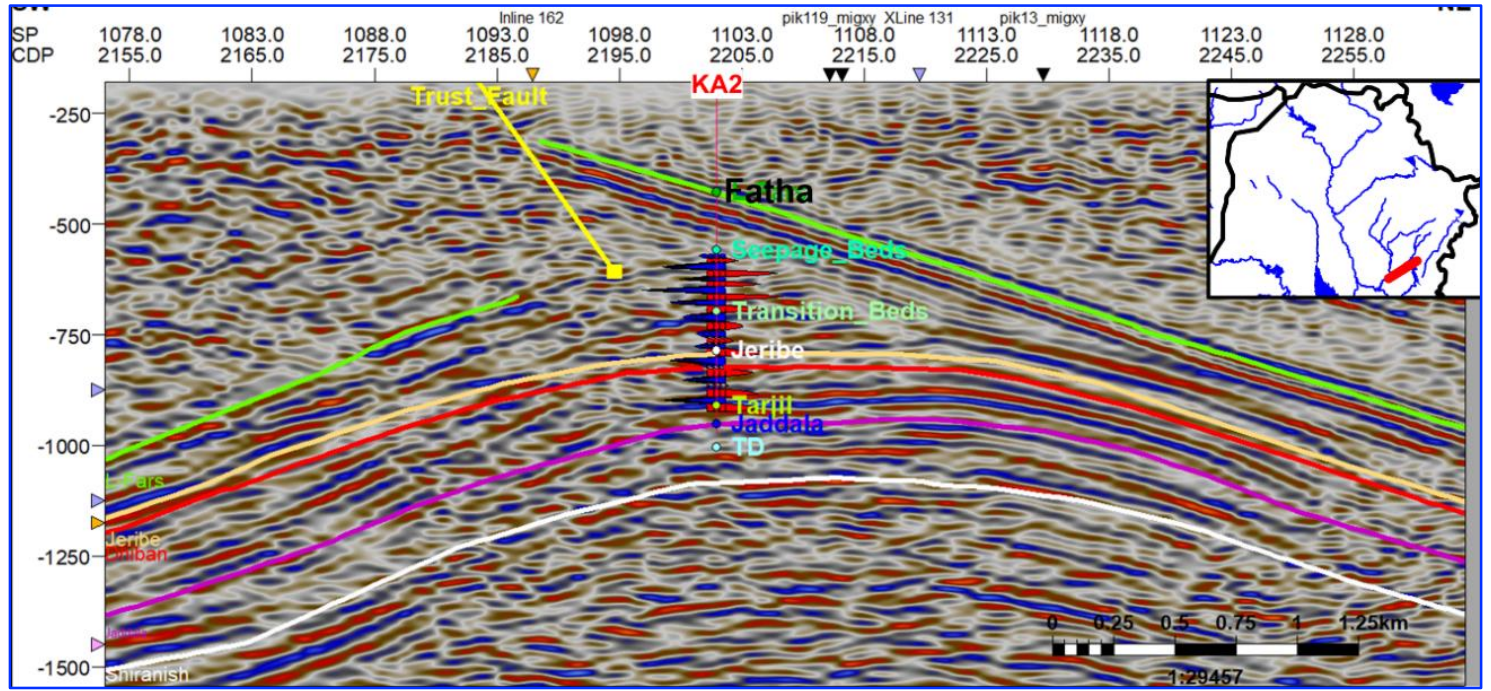

Fig.7. Illustrates PIK18 seismic line which is passing in well KA2 and illustrated thrusting in L. Fars layers with the synthetic seismogram in well KA2

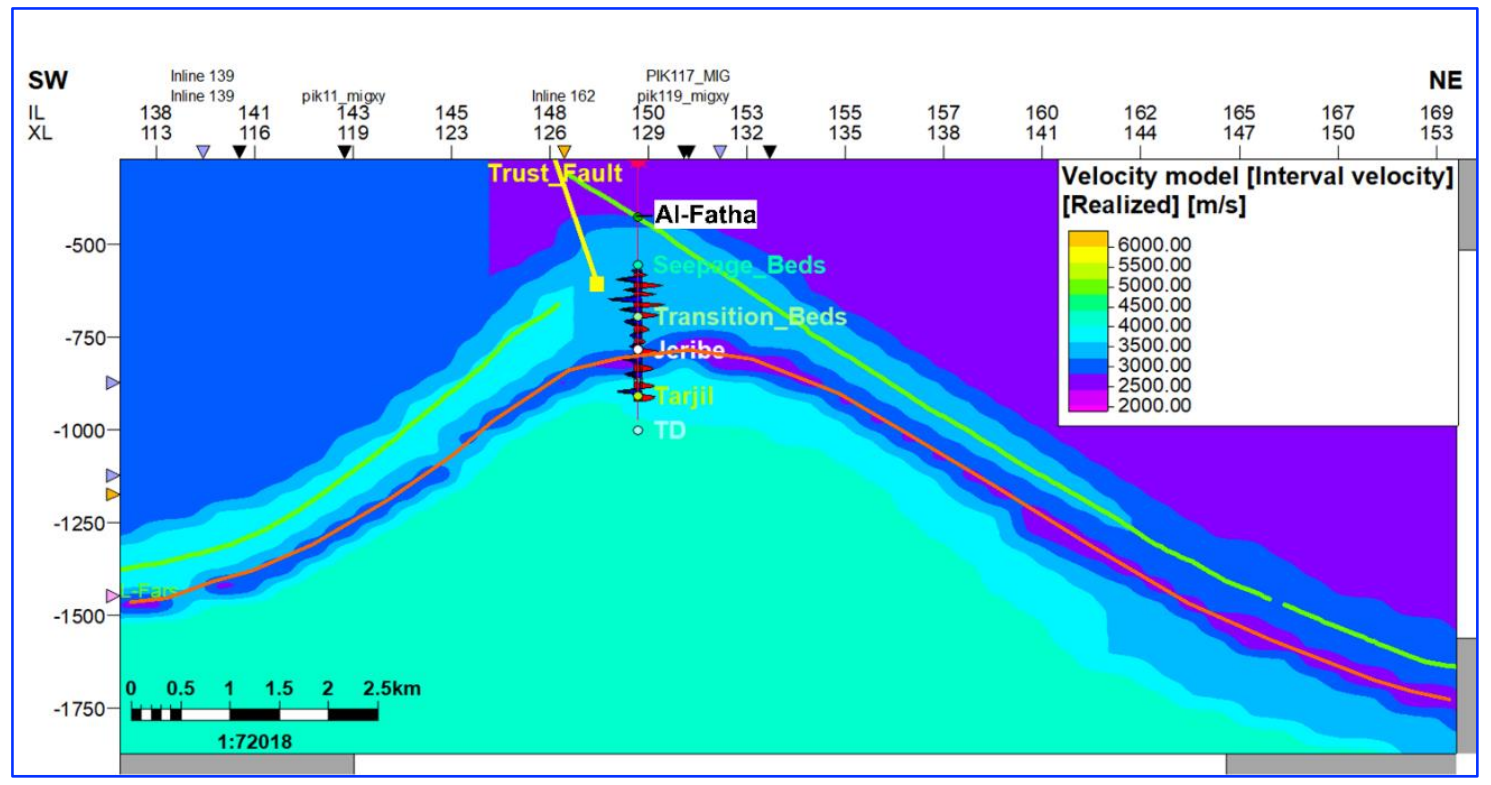

Fig.8. Illustrates 2D anisotropy velocity section located with (PIK18) seismic line

Confirmation of the presence of gas in the Jeribe reservoir through a drop in the anisotropy velocity values. This is clearly observed in (Fig. 9) were the zonation by decreasing velocity on the side of the cube where the color violate in velocity values around $(2300-2500 \mathrm{~m} / \mathrm{sec})$. Fig. 10 shows a top view slicing section for the phenomenon of decreasing velocity at the level of the Jeribe reservoir due to the presence of gas.

Fig. 11 represents the conformity of the behavior of the heterogeneous velocity section (PIK118) where it was observed in the velocity section where the presence of thrust fault within the layers of the Al-Fatha Formation., also Fig. 11 illustrated 2D anisotropy velocity section located with PIK118 seismic line and clearly shows that the gas layer is restricted within Jeribe Fn., represented by the Violet color $(2300 \mathrm{~m} / \mathrm{sec})$ value. 


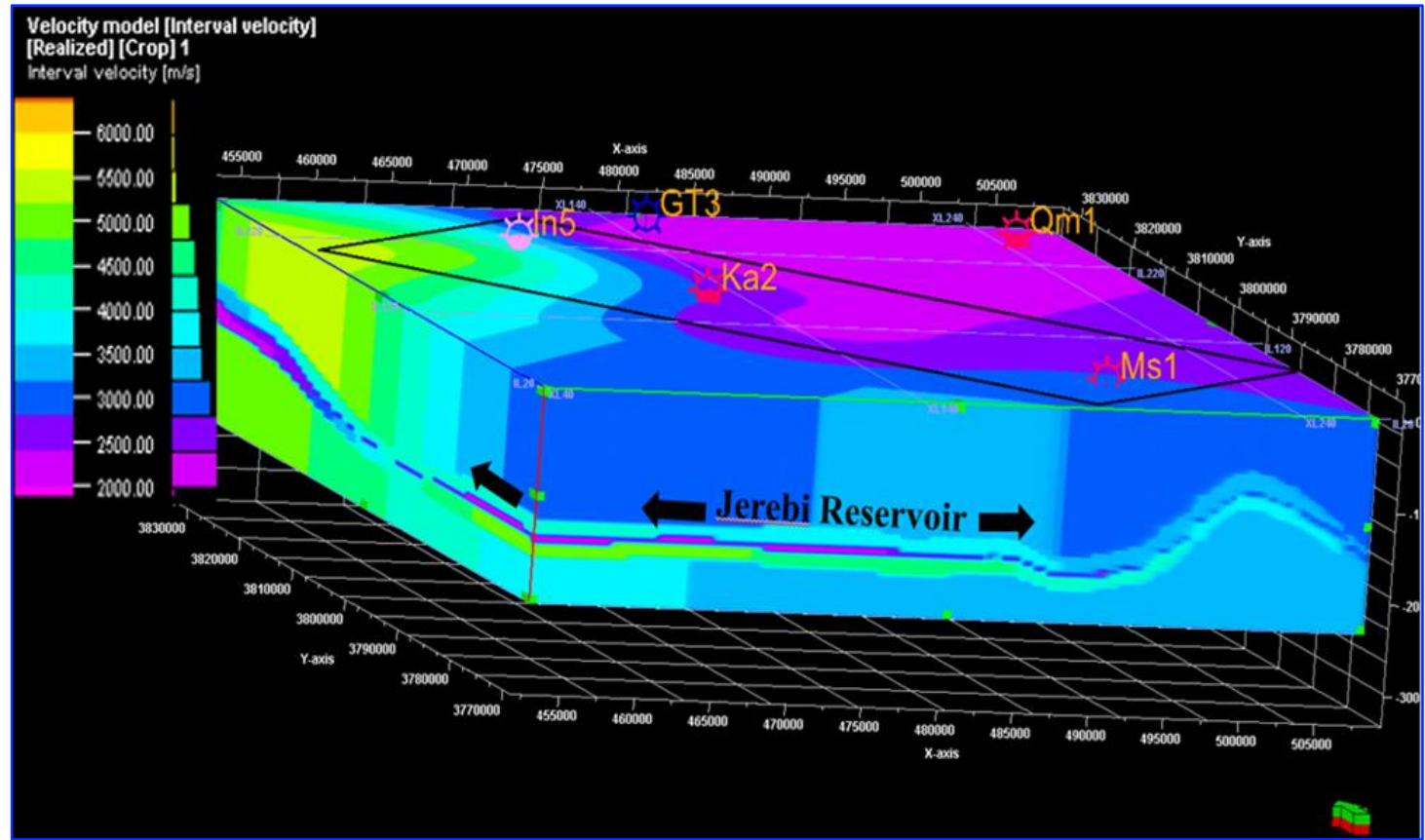

Fig.9. Illustrates anisotropy 3D velocity model, which is derivative from five wells sonic logs, and shows the variation in velocity in the Khashim Al-Ahmer gas field and its surround and it shows the heterogeneous velocity decrease in the level of the Jeribe reservoir

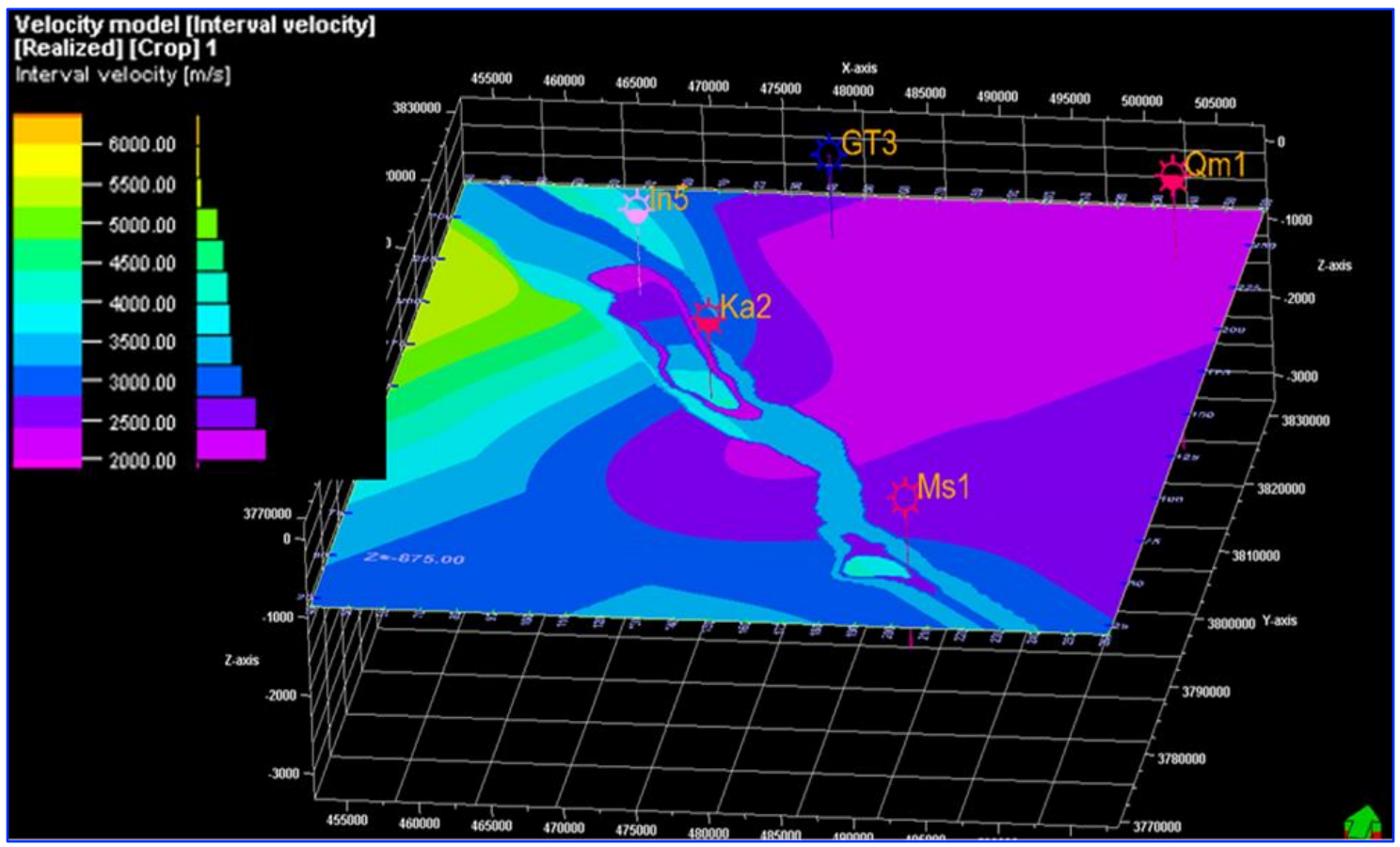

Fig.10. Illustrates slicing vertical top view section the heterogeneous variation in the velocity and its decrease in the level of the Jeribe reservoir 


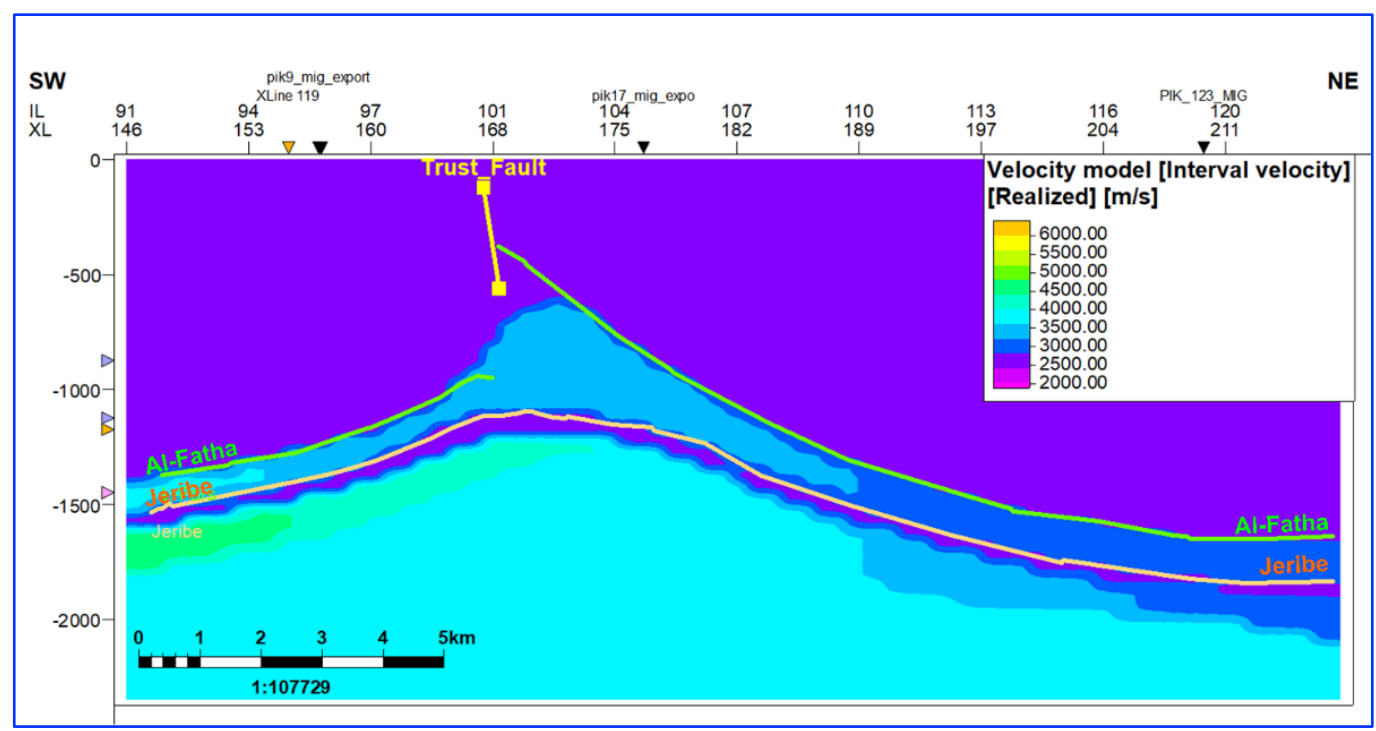

Fig.11. Illustrates 2D anisotropy velocity section located with (PIK118) seismic line

\section{Discussion}

Through the results of the current interpretation anisotropic velocity, has been reached exist system thrust fault within Fatha Formation layers. And this is causes a weak in seismic energy in these places due to the attenuation of the seismic due to the thrust fault in the layers of the Fatha Formation and the presence of gas in the Jeribe reservoir, which works on a sharp decline in seismic velocity, all of these artifact it causes confusion for the interpreter however, through the interpretations of the inhomogeneous velocity, the thrust fault was clarified, and the gas reservoir was determined by observing decreasing the inhomogeneous velocity value due to the effect of gas.

In order to increase the accuracy of the interpretations through the seismic velocity in the layers, the vertical seismic profiling (VSP) technique is the optimal solution to treat all the obstacles that cause the attenuation of the seismic velocity; Thus, this technique is considered one of the operations that must be implemented in the future in areas of geological complexity in particular.

\section{Conclusions}

This research is considered a secondary support for the seismic interpretation process and a good helper in facilitating critical decision-making for geophysical interpreters. The following can be concluded from this research: Seismic velocities derived from well logs are especially important in seismic processing to derive anisotropic strata which leads to new interpretation results. In many cases, the seismic data are of poor quality and the process of their interpretation is ambiguous, so interpretations using the wells velocities are especially useful if there are wells data in the area. Creating anisotropic velocity model for Khashim Al-Ahmer gas field gives new results to identify the boundary of the gas reservoir and confirmed that the thrust faults are within the layers of the Al-Fatha Formation only. The analysis results are of great importance for the Jerebi reservoir to be an ideal restricted gas reservoir with no gas leakage from it. The effect of the gas in the Jeribe reservoir was easily tracked through the low velocity in the Jeribe reservoir, and this greatly facilitates the direction of drilling in the future if it was decided to drill additional wells. 


\section{Acknowledgements}

The authors are grateful to the Ministry of oil for facilitating them to looking at the studies in the central library of the Ministry, and to work on their systems. The authors are very grateful to the Editor in Chief Prof. Dr. Salih M. Awadh, the Secretary of Journal Mr. Samir R. Hijab. and the Technical Editors for their great efforts and valuable comments.

\section{References}

AL-Banna, A. S., \& Al-Karadaghi, S. S., 2018. Integration study of a new gravity and seismic survey along NESW Profile in Al-Najaf Desert. Iraqi Journal of Science, 59(1B), 314-328.

Al-Chalabi, M., 2014. Principles of seismic velocities and time-to-depth conversion. Anthropocene, 26, 488.

Backus, G.E. 1962. Longwave elastic anisotropy produced by horizontal layering. Journal of Geophysical Research, 67, 4427-4440.

Jassim, S. Z., and Goff, J. C., 2006. Development of the Northern Arabian Plate, Oligocene-Recent Compression, and continental collision, P34, Geology of Iraq, Published by Dolin, Prague and Moravian Museum, Brno, 2006.

Khorshid, S. Z., \& Owiad, J. I., 2015. Sub-surface investigation of Khashim Al-Ahmer Gas Field using seismic reflection data. Iraqi Journal of Science, 56(1C), 774-784.

McBarnet, A., 2008. Why anisotropy can no longer be ignored. Offshore Engineer, 4.

Tsvankin, I., 2001. Seismic signatures and analysis of reflection data in anisotropic media: Elsevier Handbook of Geophysical Exploration, 459

Yilmaz, Ö., 2001. Seismic data analysis: Processing, inversion, and interpretation of seismic data. Society of Exploration Geophysicists, 74170-2740. 